\title{
Detenciones arbitrarias y función policial: una mirada crítica
}

\author{
José M. Maitini | Universidad Nacional de La Plata
}

Revista Derechos en Acción

Año 3/Nº 9 Primavera 2018, 483-501

DOl: https://doi.org/10.24215/25251678e236

ORCID: https://orcid.org/0000-0003-0866-682X

Resumen: El siguiente trabajo se enmarca dentro del Seminario de Grado para la finalización de la carrera de Abogacía de la UNLP del año 2018. Dentro del marco del seminario "Abogacía Popular y Derecho Crítico. Una mirada alternativa del derecho y del ejercicio profesional" (dirigido por la Dr. Carola Bianco), uno de los ejes de estudio fueron las detenciones arbitrarias y la criminalización por estereotipo. El trabajo se orienta en sendas temáticas, con la inclusión de un segundo apartado que incluye reflexiones a la posibilidad de los agentes policiales de vestirse de civil durante las manifestaciones públicas, sus alcances y limitaciones. ${ }^{1}$

\section{Un poco de historia}

"Entonces, como siempre, en el mecanismo del poder ha existido una utilización estratégica de lo que era un inconveniente. La prisión fabrica delincuentes, pero los delincuentes a fin de cuentas son útiles en el dominio económico y en el dominio político. Los delincuentes sirven"

Michel Foucault, Microfísica del poder (1980)

Agradezco la lectura y corrección de Abog. Damian Brumer y de la Dra. Carola Bianco. A ellos mi más afectuoso cariño. Agradezco también a Sabino que, habiendo finalizado sus veinticinco (25) años preso, me dio el privilegio de haberme recibido con él. Él fue mi mayor seminario. 
Cuando hablamos de teoría del derecho penal nos referimos al estado administrando castigo. La administración de castigo es una manifestación del ejercicio de la violencia legítima del estado, como afirmaba Max Weber. Un mecanismo de poder que se pone en funcionamiento ante una conducta ilícita y que trae como consecuencia una pena (un hecho político). Hay cuatro causas (legales) por las cuales (hoy) una persona puede ser detenida: a) por cometer un delito (acción típica, antijurídica, culpable y reprochable) b) por ser sorprendido in fraganti comentiéndolo; c) por contravención y d) (la tan famosa) "averiguación de antecedentes". Ponemos comillas a ésta última opción por una simple razón: en esta primera parte del trabajo vamos a problematizar su concepto. Intentaré demostrar, como afirma Foucault, la utilización estratégica del inconveniente.

En el plano nacional, el viejo Decreto Ley 333/58 establecía que eran facultades de la policía federal: "detener con fines de identificación por veinticuatro (24) horas, a toda persona de la cual sea necesario conocer sus antecedentes" (Ministerio de Justicia y Derechos Humanos, 1958) ${ }^{2}$. Una clara inconstitucionalidad de esos años; años del peronismo proscripto: una restricción a la libertad ambulatoria que violentaba la función elemental de la policía, que es ejercer la coacción directa ${ }^{3}$. La detención por "averiguación de antecedentes" del antiguo decreto ley no tenía (ni tiene) ningún tipo de justificación constitucional: no hay lesión ni peligro concreto de lesión. No hay delito de ningún tipo, sólo una mera peligrosidad "sobrante" por tener

2 En línea en: http://servicios.infoleg.gob.ar/infoleglnternet/anexos/20000-24999/20983/ norma.htm

3 Entendemos la coacción directa como la posibilidad de detener un curso lesivo actual e inminente, tal como lo analiza Zaffaroni en su Manual de Derecho Penal (6ta Edición). En este caso, el "antecedente" no tiene que ver con ningún curso lesivo "actual e inminente". Por esos años, se utilizaba esta norma para detener (simplemente) por "peligrosidad residual"; como bien se podría decir hoy con las prisiones preventivas (eufemismo para no tener que que decir pena anticipada) de algunos ex-funcionarios del anterior gobierno. Por esas épocas también se detenía por otro mérito policial: su olfato. El policía conoce la calle, el policía olfatea el delito y al delincuente. El panorama violentaba (y aún hoy quizá violenta también) la presunción de inocencia constitucional. 
"alguna antigua relación" con un hecho delictivo "ya pagado". Las comillas usadas son varias puesto que era (y a veces son) los argumentos utilizados para detener. Para ir destruyendo algunos mitos y dejar mi postura clara desde un principio: la "averiguación de antecedentes" (mejor sería decir, "averiguación de identidad") culmina, estrictamente, cuando uno muestra su DNI. Cuando uno muestra el documento nacional de identidad. Allí termina toda indagación. Sin embargo parece ser que, como lo plantea el antiguo decreto, allí no termina nada sino todo lo contrario. Allí comienza.

En 1991, la ley $23.950^{4}$ reformó este punto crucial. De la "averiguación de antecedentes" se pasó al nuevo inciso, que marcaba que se podía detener con orden de juez competente. Pero inmediatamente afirma: Sin embargo. Es decir, puede no haber orden de juez y sin embargo, ser detenido siempre que "existiesen circunstancias debidamente fundadas que hagan presumir que alguien hubiese cometido o pudiere cometer un hecho delictivo y que no haya acreditar fehacientemente su identidad" (Ministerio de Justicia y Derechos Humanos, 1991). Establecía también otros motivos: "en ningún caso podrá ser demorado por tiempo máximo de diez horas" (ídem); también se establece la prohibición de ser alojados en los mismos espacios donde se detienen a aquellos que cometieron delitos o contravenciones. Las "razones debidamente fundadas" es expresión poco amigable, de muy poca precisión legislativa, que vulnera el principio de inocencia y que deja al arbitrio de la policía de turno (a merced del que tiene el arma, de quien ostenta la fuerza) la posibilidad de detener. La fuerza-ley en este caso acompaña la fuerza simbólica de quien porta un arma y quien es llamado a mantener el orden y la paz social ${ }^{5}$. La noción en la cual se establece que nadie puede arrestado sino en virtud de orden escrita

\footnotetext{
4 En línea en: http://servicios.infoleg.gob.ar/infoleglnternet/anexos/0-4999/350/norma.htm

5 En la segunda parte del trabajo voy a hondar en la justificación necesaria de que existan las fuerzas policiales, en todo la importancia que suponen para una Nación. Sin embargo, la estructura del orden social se configura de manera tal que son en ellos (paradójicamente) en donde se descarga la primera herramienta para violentar las garantías constitucionales.
} 
de autoridad competente (tal como lo menciona la constitución nacional en el art. 18) queda totalmente desvirtuada.

Pero la normativa en cuanto a las detenciones arbitrarias y las funciones de los policías no se agota allí. La ley 13. 482 de la Provincia de Buenos Aires, en el año 2006, establece en su artículo 13 que el personal de policía deberá adecuar su conducta bajo los principios básicos de actuación policial para: "prevenir el delito y proteger a la comunidad (Ley de Unificación de las normas de organización de las policías de la Provincia de Buenos Aires, 2006) ${ }^{6}$; también el policía debe "observar en su desempeño responsabilidad, respeto de la comunidad, imparcialidad e igualdad en el cumplimiento de la Ley"; como también "asegurar la plena protección de la integridad física, psíquica y moral de las personas bajo su custodia" (ídem); o "no cometer, instigar, tolerar ningún acto de corrupción" El inc. f del mismo artículo hace mención a la "coacción directa" previamente mencionada y "utilizar la fuerza en la medida estrictamente necesaria". Por otro lado, una actuación llamativa de escaso incumplimiento es el inc. g, que dicta: "cuando el empleo de la fuerza y de armas de fuego sean inevitables, se deben identificar como funcionarios policiales y dar una clara advertencia de su intención de emplear la fuerza o armas de fuego" (ídem).

¿Imaginan a un policía dando la orden, advirtiendo, que va a utilizar la fuerza, en pleno caos social? Otra pregunta que deja pensando también: ¿cuándo el empleo del arma de fuego es inevitable y cuando es evitable? Siempre se dejará al análisis del caso concreto. Pero aun así, la redacción legislativa es ambigua. Todo muy confuso. Todo muy abierto al vértigo de sus interpretaciones.

Un gran profesor de esta casa de estudio dijo "Creo en el derecho, no le creo al derecho". Todos sabemos que el derecho no se cumple. Que las leyes están y sin embargo se incumplen. Todos sabemos que muchos derechos nacen muertos. De allí que no le creamos. No le creemos al derecho cuando pide

6 En línea en: http://www.gob.gba.gov.ar/legislacion/legislacion/l-13482.html 
"utilizar la fuerza en la medida estrictamente necesaria" porque nada de esto se cumple. Todo lo citado previamente al lector le parecerá un buen acto de comedia teniendo en cuenta los hechos que vienen sucediendo en los últimos años: policías encapuchados, patentes ocultas, policías vestidos de civil $^{7}$, cuerpos en los ríos, tiros por la espalda... en definitiva: la realidad choca de lleno con el texto de la ley. Pero sin ley, sin embargo, tampoco hay organización social ni lucha posible: de allí que creamos en el derecho y no $a$ él.

Pero continuemos. El artículo 15 establece que la policía está facultado para "limitar la libertad de las personas únicamente (el subrayado es propio) en los siguientes casos: "a) orden emanada de autoridad competente b) supuesto del Código Penal Procesal o ley contravencional de aplicación al caso" (ídem) y en su inc. c "cuando sea necesario conocer su identidad, en circunstancias que razonablemente lo justifiquen, y se niega a identificarse o no tiene la documentación que lo acredita (...) por un término no mayor de 12 horas" (ídem).

Hemos dicho que las detenciones por "averiguación de antecedentes" no tiene ningún justificativo constitucional y que las "circunstancias debidamente fundadas" comprende un término ambiguo, de interpretación hondamente laxa. Sin embargo, no seamos ingenuos tampoco: no deberíamos (en ciertos casos) sacar la constitución de la mochila como bandera y negarnos contra el pedido policial. Una respuesta práctica tendrá que contemplar el análisis de las correlaciones de fuerzas al momento de los hechos y ver los costos/beneficios de la reacción. En cada caso concreto tendrá que analizarse las ventajas y desventajas y obrar en consecuencia. ¿De qué se nos puede acusar al momento de la detención? ¿qué delitos son esgrimidos, habitualmente, para efectivizar una detención? Esto es lo que intentaremos responder en el siguiente apartado.

7 Éste punto voy a desarrollarlo en la segunda parte del trabajo, cuando hable de la poca identificación de los policías y de los policías vestidos de civil durante las manifestaciones públicas. 


\section{Grupo de tipos penales básicos para detener}

El grupo de tipos penales básicos por el cual se acusa a alguien de cometer un delito son básicamente cuatro: delito de resistencia a la autoridad (art. 237), delito de daños (art. 183), delito de lesiones (art. 89) y delito de intimidación pública (art. 211) (utilizado éste último de manera discrecional para las detenciones mientras se ejerce otro derecho, el derecho de huelga).

Para Matías Alejandro Mancini y Leonardo Pitlevnik (Revista de Pensamiento Penal) la resistencia a la autoridad supone "la acción punible desplegada por un particular que afecte a la administración desde fuera de ella" (S/A, en línea). Otros delitos que también se realizan desde fuera de la administración son los delitos de atentado contra la autoridad, la desobediencia a ésta, la falsa denuncia y el falso testimonio. Por otro lado, están los delitos "desde dentro de la misma", como son: a) jueces que mantienen a personas detenidas más allá de los plazos legales b) funcionarios que aceptan dádivas o exigen indebidamente su pago a un tercero. "Atentado" (aclaran los autores) no es "resistencia" (Ídem): si la primera supone una intimidación para que el funcionario haga o deje de hacer un acto propio de su función; la segunda, la resistencia, supone una oposición a la acción directa del funcionario para que, por medios violentos, no haga algo (ídem). Acá podemos observar cómo se logra la cuadratura del círculo: el policía que no cumple con su deber de proteger ni de identificarse (porque esa es una de sus funciones) pasa a detener, justificándose en lo que la ley llama "razones debidamente fundadas". Él no cumple su función, no cumple la ley; pero es el primero en obligar a hacerla cumplir en los otros. ¿Cómo no creerle al derecho así? Por supuesto que no se le cree.

Los delitos de daños implican "destruir, inutilizar, hacer desaparecer o de cualquier modo dañar una cosa mueble o inmueble o un animal, total o parcialmente ajeno" (Código Penal Argentino, en línea). Con este criterio, romper un banco de una plaza es motivo suficiente para detener. Ya uno allí comete 
delitos. Estrictamente es cierto, pero el principio de razonabilidad pondría una valla a la posibilidad de detención.

Los delitos de lesiones, como ya sabemos, se distinguen en leves, graves y gravísimos; sea que causen un daño en la salud y cuerpo del otro; sea que produjeran una "debilitación permanente de la salud, de un sentido, de un órgano, de un miembro" (ídem); sea que impliquen "una enfermedad mental o corporal" (ídem). Los dos últimos delitos son claros justificativos de una sanción de privación de libertad; el primero, sin embargo (las lesiones leves) sería también otro motivo, otra "razón debidamente fundada", para detener e imponer un castigo sobrepasando los límites razonables.

El delito de intimidación pública, por último, se configura cuando la persona "infunda temor público o suscitar tumultos o desórdenes, hiciere señales, diere voces de alarma, amenazare con la comisión de un delito de peligro común" (Ídem). Agrava cuando "se empleare explosivos, agresivos químicos o materias afines, siempre que el hecho no constituya delito contra la seguridad pública (ídem). El art. 212 suma otra variante: "el que públicamente incitare a la violencia colectiva contra grupos de personas o instituciones, por la sola incitación" (ídem).

Por la sola incitación. Como puede verse, el abanico para actuar es muy vasto. Las posibilidades para acusar a alguien de delincuencia, de acusar a alguien cuando (supongamos) se está realizando una manifestación pública, cuando se está ejerciendo el derecho de la huelga, es amplísima. La sanción con pena privativa de libertad por realizar estas conductas son los puntos nodales de los jueces para poder administrar castigo de manera anticipada. Supone también la vía libre del accionar policial para justificar una detención, por más burda que parezca. Y el Código Penal colabora en esto. Sancionando estas conductas con herramientas pocos claras, dando argumentos que justifiquen las detenciones. Para pensar de nuevo: muchas veces policías y fiscales -fundándose en la legalidad, en el derecho- terminan operando contra la legalidad, contra el derecho, violentado los principios básicos de inocencia, razonabilidad y legalidad. Esta contradicción es un 
umbral muy fino, intersticial, que se vuelve obligatorio pensar y reflexionar. ¿Qué han dicho los jueces, justamente, del derecho sobre el derecho mismo? Pasamos ahora a señalar ciertos fallos de trascendencia relacionados a la temática.

\section{Análisis jurisprudencial.}

\section{Causa Lucas Oscar s/habeas corpus preventivo y Fallo Vera}

En la Causa Oscar s/habeas corpus preventivo, la Cámara de Apelaciones y Garantías de Mar del Plata ha dicho, citando la Convención Americana de Derechos Humanos y el Pacto Internacional de Derechos Civiles y Políticos, que las facultades policiales no pueden significar "una carta en blanco para que la policía prive de libertad a cualquier ciudadano que les resulte sospechoso, ya que ello constituye un agravio para el Estado de Derecho y una injerencia arbitraria y abusiva en la intimidad de las personas" (CAyG MdP, Sala 2da c. 10852 "Wekesser, Martín s/ incidente de nulidad", rta. 4.10.2006, reg. 246, voto del señor juez Marcelo Madina al que adhieren los señores jueces Reinaldo Fortunato y Walter Dominella). La Cámara hace hincapié en la arbitrariedad policial, la afectación a la dignidad humana y la violación a la "acción privada de los hombres" (art. 19 CN). La selección policial se constituye, para la Cámara, siempre por estereotipo, lo que también Zaffaroni en su Manual de Derecho Penal llama criminalización secundaria. Ésta supone una pena a la persona por lo que sencillamente es, por encuadrar en "la cara del robo con arma", y nunca por lo que estrictamente hace.

Otra vertiente importante para morigerar esta criminalización es por medio de la utilización de la tecnología. El uso de sistemas informáticos podría utilizarse en la búsqueda de los datos de una persona determinada. Si bien la criminalización por estereotipo opera en todos partes del mundo, algunos autores creen que la tecnología sería una posibilidad para morigerarla. Habrá que ver, al mismo tiempo, que tampoco se manipule su información personal. Un equilibrio necesario que debe resguardarse. 
Lucas Oscar permaneció privado de su libertad sin posibilidad de comunicar su situación de detención a ninguna persona de confianza, cuando la misma ley 13.482 prohíbe esto. La propia Corte Interamericana de Derechos Humanos ha establecido sobre esta cuestión que: "El detenido tiene también el derecho a notificar a una tercera persona que está bajo la custodia del Estado. Esta notificación se hará, por ejemplo a un familiar, a un abogado y/o a su cónsul, según corresponda" (Corte IDH. Caso Bulacio Vs Argentina. Sentencia de 18 de septiembre de 2003. Serie C N $\left.{ }^{\circ} 100\right)$. Sofía Caravelos (2004), en Documentos por favor. La policía en las calles afirma que las detenciones policiales, en los pasillos de la Procuración General de la Corte "no eran incluidas en ningún apartado (...) las partes que remite la agencia ejecutiva al Juez de Garantías, terminan perdidos en la vorágine de las urgencias que se califican de mayor gravedad" (p. 112).

Por otro lado, el fallo Vera supone un retroceso de todo lo que venimos exponiendo. El tribunal omitió los estándares de la Corte Interamericana de Derechos Humanos en el caso "Bulacio vs Argentina" del año 2003: respeto de los derechos fundamentales, privación de libertad estrictamente sujeta a la ley y al procedimiento objetivo. El Estado, en ese fallo, asumió la obligación de garantizar la no repetición de casos como la muerte de Bulacio y de adecuar la normativa. Lo único que se utiliza como argumentos en el fallo Vera es el antiguo Decreto Ley 333/58. Si bien tiene reformas, éste se mantiene vigente y tiene conceptos vetustos como "registro de vecindad", concepto que utilizó uno de los jueces para dar vía libre a los policías a pedir identificación a cualquier persona que se mueva en algún barrio. La policía se auto-regula de esta manera, sin ningún tipo de control ni de publicidad.

Como conclusión de este apartado tenemos que aclarar que el Estado tiene la potestad de identificar a las personas, pero esto no implica que se deba convalidar la privación de libertad por mera "sospecha" o "peligrosidad". Más argumentos aún a nuestro favor cuando se sabe que la facultad se ejerce de manera selectiva y arbitraria: sin comunicación a los órganos judiciales 
y aislando al sujeto; sin darle la posibilidad de comunicación a sus familiares. El juzgado de instrucción de la 13era Nominación de Rosario declaró la inconstitucionalidad del art. 10 inc. B de la ley orgánica de la Policía Provincial 7395. Del mismo modo, en la ciudad de Buenos Aires, el Juzgado Nacional en lo Criminal de Instrucción del Dr. Marcelo Faimberg (en una causa de habeas corpus a favor de Oscar Coria) declaró la inconstitucionalidad del art. 5 inc. 1 del decreto ley 333/58, en razón de entenderse que la norma afectaba la garantía del art. 18 de la C.N, atribuida exclusivamente a los jueces y no a los policías.

Quizá nuestro problema se deba a la estructura misma del Poder Judicial y de nuestro débil control de constitucionalidad. Eugenio Zaffaroni, en un charla en la parte de postgrado del Rectorado de la ciudad de La Plata, se preguntaba en voz alta, sin encontrar respuesta (cito de memoria): “¿Cómo puede ser que, depende el juez que a uno le toque, fumarse un porrito puede ser considerado delito en un caso y en otro caso una acción privada de los hombres? ¿Cómo puede ser que la respuesta sea tan azarosa, depende qué juez te toque? Esto no lo podemos permitir. ¿Cómo puede ser que el control de constitucionalidad sea difuso, que quede en manos de todos los jueces? Cuando queda en todos es porque no queda en ninguno. Hay que pensar en un Tribunal Constitucional que de una única y posible interpretación a las muchas existentes que pueden existir". Quizá el problema resida en el mismo control que habilita estos excesos. Bien kafkiano: todo realizado en nombre del derecho y todo sin saber bien por qué. En la segunda parte del trabajo, a continuación, expondré algo más perverso aún: los policías vestidos de civil durante las manifestaciones públicas. Allá vamos.

\section{Segunda Parte.}

\section{Policía vestidos de civil, los "delincuentes" e ideas cortas}

Esta segunda parte (más kafkiana como adelantamos) quisiera comenzarla con una anécdota universitaria. El año pasado, durante las clases de práctica penales, la profesora en cuestión 
(no importa ahora el nombre, tampoco tiene sentirlo mencionarla, simplemente a los efectos de poder plantear la problemática) afirmó, de manera sobreactuada e insidiosa, que (y cito más o menos de memoria) los policías, en su función de prevención, pueden estar vestidos de civil en las manifestaciones públicas, sin identificación. Si su función es prevenir, entonces que prevengan. No bay necesidad de que utilicen uniforme. Si bien en ese momento callé, la sentencia me dejó pensando. Me permito ahora, realizando este trabajo y varios meses después, elegir no callar y poder darle (y darme) una respuesta aunque la profesora en cuestión quizá nunca se entere.

¿A qué se debe esta afirmación? Me he llegado a convencer que la respuesta es simple: a falta de información. O quizá peor: a falta de conocimiento. No hace falta ser un especialista para intuir una especie de engaño en esa sentencia de nuestra profesora en cuestión. Más precisamente en tiempos como los de ahora. Tiempos donde sobrevuela, amenazante, el "si pasa, pasa". Tiempos de deterioro del estado de derecho y tiempos de retorno al estado de policía. O quizá mejor dicho: tiempos de retorno de someterse arbitrariamente a quien manda. Como recuerdo al hombre de altas pestañas ${ }^{8}$ de Virginia Woolf y para evitar la simplificación, esta vez me detuve e intente rastrear el sustento jurídico de esta afirmación. Como le gustaría decir a la británica: lancé el espíritu al galope, persiguiendo una idea. Comparto aquí, en esta acotada crítica y en esta segunda parte del trabajo, a las conclusiones lentamente arribadas.

8 Virginia Woolf distingue entre los "lowbrow" y los "highbrow", las personas de "bajas pestañas" y las personas de "altas pestañas". En 1942, en el texto "Middlebrow" de The Death of the Moth (La muerte de la polilla y otros relatos, The Hogarth Press, p.113 y 114) Woolf define a los "lowbrow" como "al hombre o la mujer de una vitalidad pura sangre, que se monta al galope sobre su cuerpo, persiguiendo, durante toda su vida, sus propias condiciones de existencia". En tanto que la persona "highbrow" como el "hombre o la mujer de una inteligencia pura sangre, que lanza su espíritu al galope persiguiendo una idea". Los "middlebrow", del cual lleva el nombre del ensayo, están entre medio de ambos: "están entremedio a la prosecución de un objeto que no es ni el arte ni la vida, sino los dos mezclados indistintamente entre sí, y de manera algo repulsiva, al dinero, a la gloria, al poder y al prestigio". Interesante "panorama" de la naturaleza humana que realiza Woolf en este ensayo y que invito a su lectura. 
Realicemos un corte temporal y vayamos por acá, cerca en el tiempo, con el Reglamento del Ministerio de Seguridad de la (ya bastardeada mediáticamente) Nilda Garré. El decreto $\mathrm{N}^{\mathrm{o}} 2009$ del año 2010, en su punto 11, noquea de lleno la afirmación de nuestra docente: "es obligatorio para todo policía y fuerza de seguridad que intervienen en operativos, portar identificación clara que se advierta a simple vista en los uniformes correspondientes" (Ministerio de Justicia y Derechos Humanos, Infoleg, 2010).

Pero cambia el gobierno, viene la alegría y su revolución, viene Patricia Bullrich y la situación se modifica. Redactan el extravagante y polémico "Protocolo de Actuación de las fuerza de seguridad". Gran eufemismo para- en la realidad del llano- querer maniatar el derecho a la huelga. Un derecho que, justamente, se mide en el terreno. Nunca con una ley. Gran título protocolar para -ingenuamente- sostener que "el derecho de uno termina donde empieza el derecho del otro". Un alumno de derecho de primer año puede, en su inocencia intelectual, esgrimir este argumento. En un ministro supuestamente formado, esto es menos perdonable. Es muy sencillo demostrar las groserías lógicas de esta redacción, incluso tomando la propia letra del documento. Pasaré a comentarlas.

Empecemos por el primer gran error: el protocolo enumera derechos que entrarían en conflicto con los "cortes de ruta". Por un lado -nos dice el Protocolo- hay derechos como la expresión, derecho a reunión, derecho a peticionar frente a las autoridades. Por otro, se encuentra el derecho a transitar libremente. Primera crítica: las personas no se movilizan por su derecho de expresión, sino en nombre de otros derechos fundamentales (la salud, la vivienda, el trabajo). No es que llegar a casa no importe. Es simplemente entender que hay derechos, en un contexto puntual, que pelean un solo espacio. Lucha en la cual uno gana y otro, inevitablemente, pierde. Alguien tiene que decir cuál. Y más importante: alguien tiene que decir por qué.

Esta es una discusión que excede este trabajo, pero en resumidas cuentas voy a arribar a lo que quiero decir. Siempre tendrá 
que analizarse el caso concreto; pero el juez William Brennan en el famoso fallo New York Times contra Sullivan (fallo que recepta la real malicia. Fallo en momentos de represión de las marchas de Martin Luther King en los Estados Unidos) sostuvo que -frente a choque de derechos- "siempre prevalecerá el derecho que esté más cerca del nudo democrático de la constitución" ( citado de Gargarella, 2015, p. 27).

Ahora, preguntará el lector: ¿Qué me quiere decir señor William? ¿Cuál es ese nudo democrático del que habla? Para el choque de derechos que nos compete (derecho a huelga versus derecho a transitar libremente), el peticionar contra las Autoridades, contra los que nos gobiernan, prevalece sobre la posibilidad de transitar porque en un sistema republicano (como el nuestro) la discusión debe mantenerse abierta, sin trabas y desinhibida contra el gobierno y sus funcionarios. Éste es nuestro nudo democrático. Esta es la base de nuestra llamada "República". Es el pueblo, participando de la cosa pública. Es el pueblo, deliberando y gobernando por medio de sus representantes. Y cuando los derechos más trascendentes suelen ser afectados por obra y falta de sus mismos representantes, por las mismas autoridades, por el mismo Estado: ¿Cómo se puede entender querer limitar ese debate? A ésta conclusión llega William en EEUU; a ésta conclusión, salvando las diferencias contextuales, podría concluir también este caso.

Pero ahora vayamos a algo más burdo aún. Al bolazo cósmico nunca visto. Al "corte de calles" el Protocolo lo cataloga como delito de flagrancia (art. 194 Código Penal). Es decir, el piquetero como delincuente por "entorpecer el normal funcionamiento del transporte por tierra". Todo está mal enfocado. Se está hablando de delincuentes cuando el Estado es parte del problema. Están en juego derechos fundamentales y la omisión del Estado convierte a los que ejercen el derecho a huelga en delincuentes. Como se pregunta Gargarella (2015) en una de sus notas: “ $¿ S i$ el Estado omite sus obligaciones constitucionales ¿no será él, entonces, el primer criminal?” (p. 56) El sistema institucional es aciago, conlleva desgracia y se tilda de 
delincuente a los que se reclaman por vulneraciones que son -justamente- hechas por las propias manos del Estado. En la escuela del mundo del revés de Galeano, las reglas se imponen. En la escuela del mundo del revés todavía no se enseña que las reglas se construyen de manera colectiva.

Pero nos fuimos de tema. Volvamos a la identificación "a simple vista" de las fuerzas de seguridad en las manifestaciones públicas. No hay una sola mención a dicho problema en este Protocolo. He aquí que nuestra profesora podría decir: ¡Aja! ¿vio? Nada dice. Pero como nos detenemos a examinar, sin llegar rápido a conclusiones, nos chocamos con una gran sorpresa: el Protocolo no está publicado en el Boletín Oficial. Haga el mínimo esfuerzo. Lo invito a que busque. No está. Y es conocido por todos que una ley, para entrar en vigencia, es necesario y obligatorio que se publique en el Boletín. Esto llevó inclusive a Amnistía Internacional (2018) a afirmar que este Protocolo carece de formalidad ministerial, que al no estar publicado rige el anterior, el de Nilda Garré. Amnistía agregó, además, que "están preocupados por el incremento de la represión, criminalización y armado de causas contra quienes reclaman por sus derechos" . Nos dijeron convencidos que querían "volver al mundo”. Gratificante manera de hacerlo, ¿no parece?

Vayamos ahora a la ciudad autónoma de Buenos Aires, a la Provincia Buenos Aires y más precisamente a la ciudad de La Plata. Para no aburrir a esta altura, haré mención a dos o tres cosas importantes. Primero, en CABA, el art. 100 de la Ley de Sistema de Seguridad Pública replica el art. 11 de Nilda Garré: "es obligatorio la identificación clara del personal policial a simple vista en las manifestaciones públicas". Segundo, en Provincia de Buenos Aires la Ley de Seguridad Pública imita al Protocolo. Ni una sola mención al caso. Tercero, en la ciudad de La Plata, el intendente Garro buscó implementar el aberrante

9 En línea en la página de Canal Abierto, Periodismo de éste lado: http://canalabierto.com. ar/2018/04/13/amnistia-internacional-advirtio-sobre-la-erosion-del-derecho-a-la-protestaen-argentina/ 
Protocolo Anti piquete de Bullrich, previamente mencionado. En el diario El Día, el 16 de Marzo de 2016 (puede encontrarse en Internet), declaró infantilmente que "Interrumpir la circulación está rozando el delito de privación ilegítima de la libertad porque el derecho de uno termina donde empieza el derecho del otro"10. Para categóricamente determinar que "si se crea un protocolo, hay que hacerlo cumplir".

Más en crudo: quiso decir (quizá) que todo aquél que corte una ruta comete flagrancia. Que todo aquel que corta la ruta es un delincuente. Como -actualmente- lo hace el Protocolo. Por si las dudas, a Intendencia voy a mandar algunos fallos y libros. Especialmente el de New York Times contra Sullivan. Tema garantías constitucionales para Garro: te la debo. Como dijo Macri el 14 de Abril de 2016 cuando le preguntan acerca de la muerte de una auxiliar docente que falleció en Mar del Plata, mientras reclamaba porque le habían descontado 6 mil pesos por paros a los que no había adherido. Te la debo. Esa te la debo, no estoy en el tema. ${ }^{11}$

En fin. Sinteticemos. La única manera de defender la no identificación a simple vista de los policías en las manifestaciones públicas es defendiendo la validez del Protocolo Anti piquete, dado que éste no hace referencia alguna a ésta situación. Como tampoco se hace mención en la Provincia de Buenos Aires. Pero como sí lo sigue manteniendo la Ley de Seguridad Pública de CABA. La única manera de sostener esto es, entonces, creyendo también que todo aquel que corta una calle es un delincuente. Qué mejor manera de encontrar al delincuente en una manifestación si el mismo Protocolo no obliga a la identificación policial a simple vista. Uno se camufla entre "los delincuentes". Acá está la herramienta fundamental de camuflaje. Qué mejor

\footnotetext{
10 Se puede ver en línea en el siguiente enlace del diario El día: https://www.eldia.com/ nota/2016-3-17--vamos-a-impulsar-un-protocolo-antipiquetes

11 Para que acumule también un poco más de bronca el lector, éste es el enlace, del diario La Voz, donde nuestro presidente dice ésto: http://www.lavoz.com.ar/politica/te-lo-debo-noestoy-en-el-tema-dijo-macri-ante-una-pregunta-sobre-la-muerte-de-una-portera
} 
facilidad para un cazador que su presa no advierta nunca que será cazada.

Quizá en estos momentos no vendría mal recordar el discurso de Esteban Righi, Ministro del Interior durante el gobierno de Cámpora, allá por esos sesenta días de la primavera camporista. Firme, convencido, frente a todo el cuerpo policial dijo (la cita es algo extensa, pero merece la pena citarla):

“(...) Encerrados dentro de la comisaría y rodeado de vallas, fueron alejados del pueblo, sin desearlo ni buscarlo Tendrán obligaciones, que deberán cumplir ineludiblemente. Pero también tendrán los derechos que en todos estos años habían perdido. Y sus propias obligaciones serán cumplidas con un espíritu nuevo, porque implican clausurar un período de dolorosa memoria para iniciar oro más justo, más noble. Lo trágico de la situación es que nuestra Policía ha vivido es que sus jefes, oficiales y tropas han sido compelidos a enfrentarse con las masas populares de las que surgieron, y que defendían un futuro mejor también para ellos. Ésta es una enfermedad que ahora queremos curar (...) Señores, no se alejen ustedes del pueblo. Pasaremos de un orden dictatorial a un orden democrático. Nuestra terapéutica es reconstruir. No permitir. Hay tensiones acumuladas y habrá conflictos. Lo sabemos y no nos asusta. Es imposible restaurar en pocos días todo lo que se destrozó en tantos años (...) Un orden injusto se guarda con la misma violencia que lo originó. Un orden justo, por el contrario, se guarda con moderación y prudencia; un orden justo se comporta con humanidad, inclusive frente al culpable; un orden justo se guarda con respeto y con sensibilidad humana y eso en ustedes no puede ser negociado (...) Ésa es nuestra convicción y nuestra mejor garantía. Seamos dignos de ella" (citado de Feinmann, 2011, p.208).

Ahora, inevitablemente, me pregunto: ¿Qué orden de moderación y prudencia, que orden de respeto y sensibilidad se construye referenciando a todo aquél que corta una ruta como un delincuente? 
Si no se piensa seriamente lo que se dice y lo que hace caemos -quizá- en un reduccionismo mental peligroso. Pasamos por los accidentes del terreno, sin que nada llame la atención. Inevitablemente pienso: no querer que los policías sean identificados... ¿no será parte de una herramienta del Gobierno para inventar chivos expiatorios y distraer la atención pública de todos los derechos últimamente vulnerados? ¿no será acaso la posibilidad perfecta para inventar casos policiales y despistar a la población de los hechos que realmente importan? Y además - de yapa- en una represión desaparece una persona por 80 días. Y además, de yapa -al día 81- aparece un cuerpo en el río. A 300 metros del lugar donde desapareció. Cuando ya habían rastrillado tres veces la misma zona. Se ve que necesitaron una cuarta. Y de yapa, otro recibe un tiro por la espalda. Y de más yapa todavía (el lector ya a esta altura dirá "¡básta! ¡Basta de yapas! Bueno, disculpen. Por estos tiempos viene de regalo todo por lo visto) y de yapa, decía, el beneficio de la duda siempre a favor de las Fuerzas Armadas, como dijo la vicepresidente de la Nación ${ }^{12}$.

Que no tomen al pueblo por idiota supone también que el pueblo se fortalezca en la crítica. Supone también detenerse cautelosamente en los hechos. Supone no decir por decir. Supone pensamiento de largo alcance; pensamiento sin ideas cortas. Con ideas largas los bastones serán cortos, porque la arbitrariedad se encorseta si hay una idea que la contiene. Pero si las ideas son cortas, los bastones serán largos. Está en nosotros dejar (o no) que esto suceda.

\section{Bibliografía}

Agencia DyN (20169. "Te la debo, no estoy en el tema" dijo Macri ante una pregunta sobre la muerte de una portera" en diario $L a$

\footnotetext{
12 Y ahora con la resolución 956/2018 de Patricia Bullrich nada más que aclarar: el uso de armas de fuego utilizadas ante cualquier "peligro inminente" o "presunción de que el sospechoso tenga un arma letal". Se usa el arma de fuego para "proceder a la detención", para quien "oponga resistencia", para quién "se fuga y represente peligro inminente". Todo una aberración lo de la Ministra y, por consiguiente de quien la elige, el Ejecutivo. Con esta resolución no se hace otra cosa que reglamentar una pena de muerte encubierta.
} 
Voz. 14 de Abril de 2016. En Línea en: http://www.lavoz.com. ar/politica/te-lo-debo-no-estoy-en-el-tema-dijo-macri-anteuna-pregunta-sobre-la-muerte-de-una-portera

Cámara de Apelaciones y Garantías de Mar del Plata (2014). Causa Oscar s/habeas corpus preventivo. Resolución Serie "B" No 29. Expte. $N^{\circ}$ 18.270. Autos: "Lescano Oscar Alberto s/ Recurso de Habeas Corpus - Habeas Corpus". Buenos Aires, Argentina.

Caravelos, Sofía (2003). "Documentos por favor. La Policía en las calles”, en González Moras, Juan y otros. Criminalización de la protesta social. Ediciones Grupo La Grieta y Agrupación H.I.J.O.S. La Plata, Argentina.

Congreso de la Nación Argentina (1958). Decreto-ley $N^{o} 333$. Ministerio de Justicia y Derechos Humanos. Información Legislativa. En línea en: http://servicios.infoleg.gob.ar/infolegInternet/ anexos/20000-24999/20983/norma.htm

- (1991) Ley $N^{o}$ 23.950. Información Legislativa. Ministerio de Justicia y Derechos Humanos. En línea en:

http://servicios.infoleg.gob.ar/infolegInternet/anexos/ 0-4999/350/norma.htm

- (2017). Código Penal de la Nación Argentina. Ley No 11.179. En línea en: http://servicios.infoleg.gob.ar/infolegInternet/ anexos/15000-19999/16546/texact.htm

- (1960). Administración Pública Nacional. Decreto-ley $N^{o}$ 2009/2010. Ministerio de Justicia y Derechos Humanos. Información Legislativa. En línea en: http://servicios.infoleg.gob.ar/infolegInternet/anexos/175000-179999/177671/ norma.htm

Congreso de la Provincia de Buenos Aires (S/A). Ley de Unificación de las normas de organización de las policías de la provincia de Buenos Aires. $N^{\circ} 13482$. En línea en: http://www.gob.gba. gov.ar/legislacion/legislacion/l-13482.html

Feinmann, José Pablo (2011). Peronismo Tomo II. Filosofía politica de una persistencia Argentina. Editorial Planeta. Buenos Aires, Argentina.

Gargarella Roberto (2015). Carta abierta sobre la intolerancia. Apuntes sobre Derecho y Protesta. Siglo Veintiuno Editores. Buenos Aires, Argentina. 
Mancini, Matías Alejandro y Pitlevnik, Leonardo (S/A). Atentado contra la autoridad. Código Penal Comentado de Acceso libre. Asociación Pensamiento Penal. Buenos Aires, Argentina.

Redacción Canal Abierto (2018). "Amnistía Internacional advirtió sobre "la erosión del derecho a la protesta" en Canal Abierto, Periodismo de éste lado. En línea en: http://canalabierto. com.ar/2018/04/13/amnistia-internacional-advirtio-sobre-laerosion-del-derecho-a-la-protesta-en-argentina/

Redacción Diario El Día (2016). "Vamos a impulsar un protocolo antipiquetes" El intendente Garro lo enviará al Concejo Deliberante en Diario El Día. 17 de Marzo de 2016. En línea en:

https://www.eldia.com/nota/2016-3-17--vamos-a-impulsar-unprotocolo-antipiquetes

Tribunal Superior de Justicia de la Ciudad (2015.) Causa Vera, Lucas Abel. Expediente No 11835/15. Buenos Aires, Argentina. Woolf, Virginia (1942). "Middlebrow" en The Death of the Moth. The Hogarth Press. Londres, Reino Unido. 